\title{
Call for Special Issue Papers: Disparities During Times of a Pandemic and Epidemic
}

\author{
Deadline for Manuscript Submission: June 15, 2020
}

\author{
Editor-in-Chief: Sylvia Hood Washington, PhD, ND, MSE, MPH, CLT-LANA; \\ Chief Lymphatic Clinician: Environmental Health Research Associates, LLC
}

The United States' response to the novel coronavirus (COVID-19) pandemic - first detected in the United States in late January 2020 before cases began appearing across the entire country - underscored tremendous challenges faced around the nation and the globe in containing the spread of the disease and planning for recovery efforts.

Certain groups within the United States, such as those living in poverty, minorities, the elderly, those suffering from immune and respiratory disorders, the obese, and persons living in areas with increased air pollution, are at an increased risk for experiencing disparities related to the disease. The recommendation and implementation of the public health directive to stay inside and self-isolate also places a burden on communities that lacked resources prior to the outbreak, particularly those whose communities were suffering from poor nutritional resources.

Environmental Justice invites manuscript submissions related to the challenges seen in these populations during times of a pandemic. All manuscripts should be submitted online using the ScholarOne submission site by June 15,2020 . All submissions will be subject to a rigorous

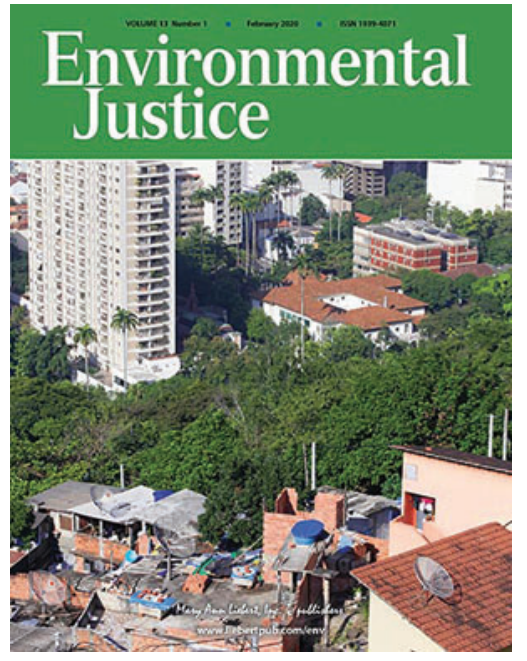
peer review. We encourage submissions of original research articles, reviews, and perspectives.

\section{Suggested topic areas include, among others:}

- Disparities experienced during a pandemic by those with certain health conditions

Diabetes

Obesity

Asthma

Autoimmune disorders

High blood pressure

COPD

- Recommendations for caring for immunocompromised individuals

Compromised lymphatic system

Generational and genetic predisposition

- The experience of pandemics for persons living below the poverty line

- Financial impact for families

Uncertainties surrounding necessities (food, supplies, housing)

Forced unemployment

Economic stimulus packages

Visit the Environmental Justice website to learn more, read past issues, and view author submission guidelines.

Queries to the editor to propose a topic prior to submission are encouraged. Please contact Editor-in-Chief Dr. Silvia Hood Washington to initiate your query or for any further details.

Visit the Instructions for Authors: www.liebertpub.com/env

Submit your paper for peer review online: https://mc.manuscriptcentral.com/env 